\title{
miRNA-21 plays an important role in necrotizing enterocolitis
}

Wen Li, Xiaoyang Huang, Dan Bi

Department of Pediatrics, Qilu Hospital of Shandong University, Ji'nan, Shandong, China

Submitted: 24 March 2019; Accepted: 31 May 2019

Online publication: 17 September 2019

Arch Med Sci 2022; 18 (2): 406-412

DOI: https://doi.org/10.5114/aoms.2019.88013

Copyright $\odot 2019$ Termedia \& Banach

\section{Abstract}

Introduction: To investigate the role and mechanism of miRNA-21 in necrotizing enterocolitis (NEC).

Material and methods: Collecting 30 pairs of newborn and NEC children and measuring the miRNA-21 expression in the serum of 30 pairs. Thirty neonatal Wistar rats were randomized to 3 groups: NC, Model and miRNA groups. The rats of model and miRNA groups were based on NEC model groups, after the fabricated NEC model of neonatal rats. The Model group was treated with normal saline and the miRNA group was injected with miRNA-21 from the abdomen. On the $4^{\text {th }}$ day, all the rats were executed. The intestinal tissue located at the boundary of the ileum and cecum was sampled for histology and cell apoptosis. The relative protein (PTEN, PI3K, AKT and GSK-3 $\beta$ ) expression levels of difference groups were evaluated by WB assay.

Results: In the clinical data, the miRNA-21 gene expression of NEC children was significantly up-regulation compared with that of normal newborns $(p<0.05)$. In the rat experiments, compared with the NC group, the pathology and cell apoptosis of the Model group showed significant deterioration $(p<0.05)$ and relative protein (PTEN, $p$-PI3K, p-AKT and p-GSK-3 $\beta$ ) expression levels were significantly different ( $p<0.05$, respectively). However, the pathology and cell apoptosis of colonic tissue were significantly improved $(p<0.05)$, the PTEN and $p-G S K-3 \beta$ protein expression levels were significantly suppressed $(p<0.05)$ and $p-P I 3 K$ and $p$-AKT protein expression levels were significantly increased ( $p<0.05$, respectively) with miRNA-21 over-expression compared with the Model group.

Conclusions: miRNA might be a biological marker and therapeutic target in NEC diagnosis and treatment.

Key words: miRNA-21, NEC, cell apoptosis, PTEN/PI3K/AKT/GSK-3ß.

\section{Introduction}

Necrotizing enterocolitis (NEC) is the most common life-threatening intestinal surgical disease in the neonatal stage, especially in premature infants. The incidence of necrotizing enterocolitis is higher with the decrease of body weight and gestational age. National Institute of Child Health and Human Development (NICHD) reported that more than $90 \%$ of NEC infants were under 36 weeks of gestation, and $15 \%$ of the infants had birth weight below $600 \mathrm{~g}$. The incidence of NEC in very low birth weight (VLBW) infants and extremely low birth weight (ELBW) infants was 5\% and 10\%, respectively [1-4]. With the strengthen-

\author{
Corresponding author: \\ Wen Li \\ Department of Pediatrics \\ Qilu Hospital \\ of Shandong University \\ 107, Wenhua West Road \\ Ji'nan 250012 \\ Shandong, China \\ E-mail: liwenmm1117@sina. \\ com
}


ing and improvement of neonatal care measures, the survival rate of preterm infants has gradually improved, but the incidence of NEC has gradually increased, and the clinical treatment of NEC has made little progress in recent years [3]. Recent trends indicate that NEC is likely to become the leading cause of premature infant death in the United States. Preterm delivery, gastrointestinal immaturity, hypoxia, artificial feeding, bacterial transplantation and hypoperfusion are the major risk factors for NEC. Preterm birth is the single most dangerous factor, and excessive inflammation is the main part. But the NEC pathogenesis is complex, and the specific pathogenesis has been not very clear.

Phosphatase and tensin homology deleted on chromosome ten (PTEN)/phosphoinositide-3 kinase $(\mathrm{PI} 3 \mathrm{~K}) /$ serine/threonine (AKT)/glycogen syn-

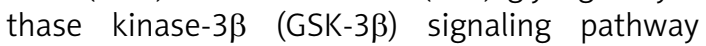
played important roles in energy metabolism, apoptosis, differentiation and reproduction [5-7]. Recent studies found that miRNAs could regulate cell apoptosis and proliferation by relative pathways [8-10]. miRNA-21 has an important role in the miRNA family $[11,12]$. In previous studies, the results showed that PTEN was a target gene of miRNA-21 [13, 14].

In our present study, we wanted to explain the effect and mechanism of miRNA-21 in the development of NEC.

\section{Material and methods}

\section{Clinical data}

Thirty pairs of normal newborn and NEC children who were treated and born in our hospital from 2015.6 to 2016.6 were collected and the venous blood was taken.

\section{Animals and grouping}

Thirty newborn Wistar rats aged 1 day, body weight was 5.5-10 g, were purchased from Shandong University Medical School. The rats were divided into 3 groups. There were 10 rats in every group. The NC group was injected with $0.2 \mathrm{ml}$ of normal saline; the Model group was injected with $0.2 \mathrm{ml}$ of normal saline based on the model; the miRNA group was injected with $0.2 \mathrm{ml}$ of miRNA-21 which was purchased from Gen Script (Nanjing) Co., Ltd (Nanjing, China) based on the model. All the drugs were administered by the intraperitoneal injection route. Rat pups are separated from their mothers at $24 \mathrm{~h}$ after birth, room temperature was maintained at about $21^{\circ} \mathrm{C}$, natural lighting, with the formula Mead Johnson infant oral feeding in neonatal rats $(200 \mathrm{kcal} / \mathrm{kg} /$ day), feeding $3 \mathrm{~h}$ /once, $0.1 \mathrm{ml}$ each time, and increasing the diet with body weight increasing.

\section{RT-PCR}

The total mRNA was extracted by Trizol which was purchased from TOYOBO (Japan), and the total mRNA concentration was measured by a UV-Vis spectrophotometer, taking $4 \mu \mathrm{g}$ of total RNA for reverse transcription into CDNA. A certain amount of cDNA was used for PCR amplification. The miRNA- 21 gene expression primer sequences were synthesized from Gen Script (Nanjing) Co., Ltd (Nanjing, China) as follows: miRNA-21 F: 5'-TCCGAAGTTGTAGTCAGACT- 3'; R: 5'-GTGCAGGGTCCGAGGT- 3'. U6 F: 5'-CTCGCTTCGGCAGCACA-3'; R: AACGCTTCACGAATTTGCGT-3'. In this experiment, we used $U 6$ as a reference. miRNA-21 mRNA expression was measured by the $2^{-\Delta \Lambda} C T$ method.

\section{NEC animal model $[15,16]$}

After zeroing the portable RSS-5100 oxygen meter, the probe was connected to the top notch of the anoxic box sealed with adhesive tape, and pure nitrogen was filled into the other notch. After the oxygen concentration in the tank dropped to zero, the newborn rats were put into the tank quickly, with nitrogen continuously filled until it reached $100 \%$, after which the environment was maintained for $10 \mathrm{~min}$. Subsequently, the rats were put into an oxygen chamber with $100 \%$ oxygen for $10 \mathrm{~min}$, and then immediately placed into a refrigerator at $4^{\circ} \mathrm{C}$ for $10 \mathrm{~min}$. The treatment was repeated 3 times a day, for a total of 9 times. After the treatment, the rats were sent back to the incubator. In addition, LPS $(10 \mathrm{mg} / \mathrm{kg})$ was diluted in $0.1 \mathrm{ml}$ of sterile water for intragastric administration once a day. The rats in different groups were administered according to their prescribed dosage for 3 consecutive days, and sacrificed by decollation on the $4^{\text {th }}$ day.

\section{Histopathological examination of intestinal tract}

1-2 cm of the proximal ileocecal tissue was fixed immediately in paraformaldehyde, paraffin embedded, sliced, and stained with H\&E staining. The pathological scores were scored by Nadler criteria: 0 points: The villi and epithelium of the intestine are intact and the tissue structure is normal; 1 point: Slight submucosal or lamina propria swelling separation; 3 point: Moderate submucosal and/or lamina propria separation, submucosal and/or muscular edema; 4 point: Intestinal villus disappearance with intestinal necrosis. The pathological score is greater than or equal to 2 points, which is considered to be the onset of NEC.

\section{TUNEL assay}

1-2 cm of the proximal ileocecal tissue was fixed immediately in paraformaldehyde, paraffin embed- 
ded, sliced, and subjected to TUNEL assay. The cell apoptosis was measured by a TUNEL kit (Roche, USA). Paraffin sections were dewaxed in xylene, followed by hydration in a gradient of alcohol; protease $\mathrm{K}(20 \mu \mathrm{g} / \mathrm{ml})$ was used for digestion for $30 \mathrm{~min}$ at $37^{\circ} \mathrm{C}$, mixed reaction solution containing terminal deoxynucleotidyl transferase and fluorescein

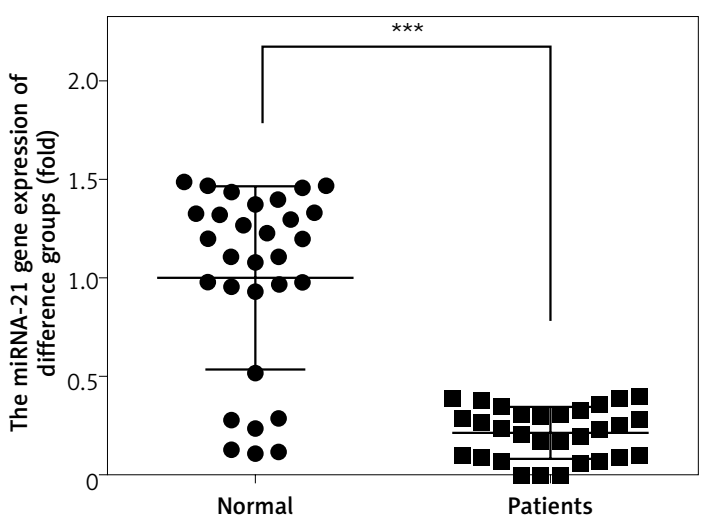

Figure 1. miRNA-21 gene expression of NEC and normal children

${ }^{\star * *} P<0.05$, compared with normal children.

NC

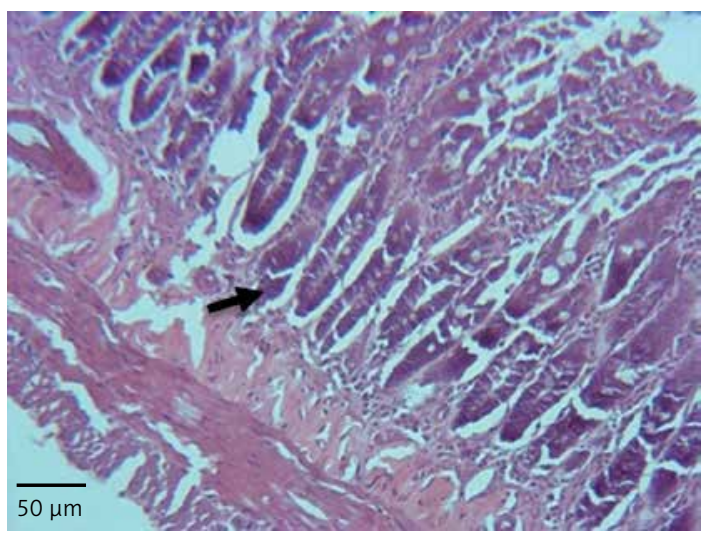

miRNA
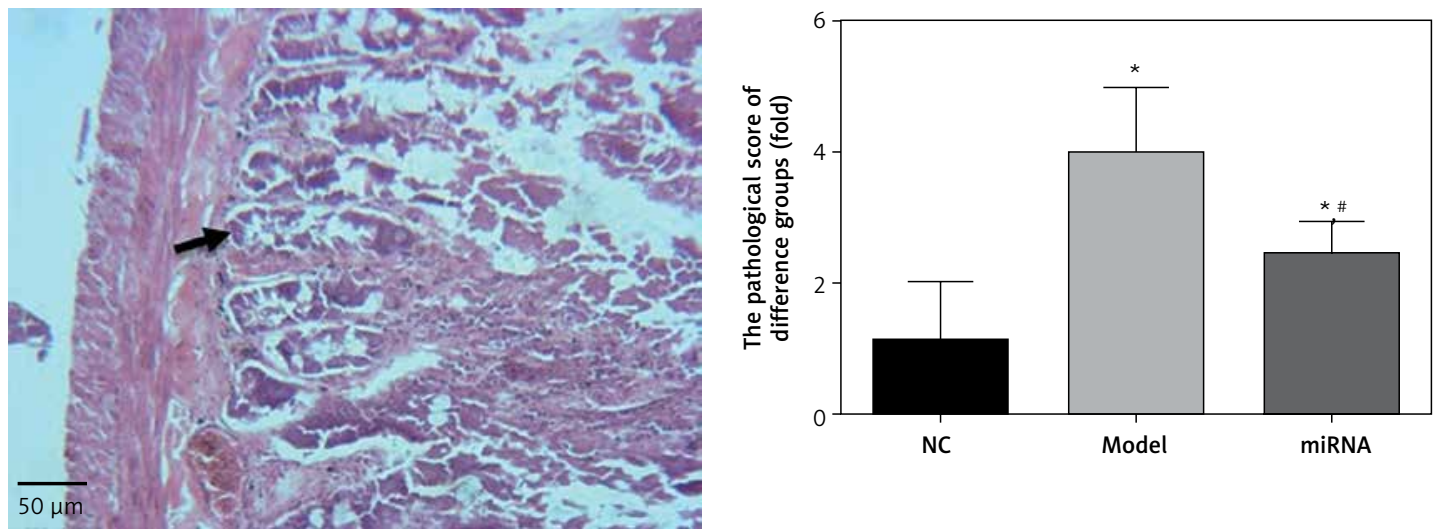

labeled dUTP were added to culture for $1 \mathrm{~h}$ at $37^{\circ} \mathrm{C}$, followed by adding anti-fluorescein antibodies linked to alkaline phosphatase to culture for $30 \mathrm{~min}$ at $37^{\circ} \mathrm{C}$, hematoxylin light lining dye, dehydrated, transparent, mounting, observation under light microscope and measuring the cell apoptosis rate.

\section{WB assay}

The total protein of proximal ileocecal tissue was extracted, and we measured the concentration by the spectrophotometer method, trim as $2 \mathrm{~g} / \mathrm{l}$, electrophoresis by $10 \%$ SDS-PAGE. After the film was transferred by the wet rotating method, it was put into the closed liquid, and the $2 \mathrm{~h}$ was closed on the shaking table. The first antibody was added to culture at $4^{\circ} \mathrm{C}$ overnight. After that, the second antibody was added to culture at room temperature overnight. After exposure in a darkroom, developing and fixing. The GAPDH was considered as a reference in this study. The relative antibodies (PTEN, PI3K, p-PI3k, AKT, p-AKT, GSK-3 $\beta$ and GAPDH) were purchased from Abcam (USA) and $p$-GSK-3 $\beta$ was purchased from Cell Signaling (USA). PTEN (ab32199, Abcam, USA); PI3K (ab32089, Abcam, USA); p-PI3K (ab182651, Abcam,

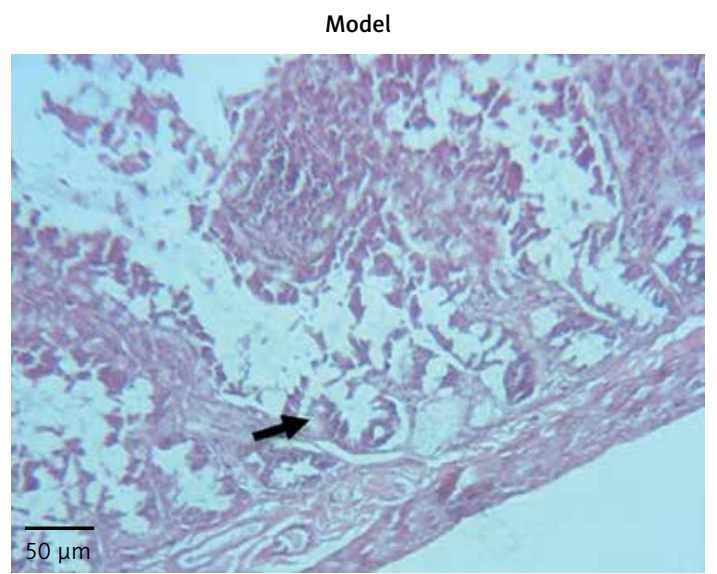

$\mathrm{NC}$

Model

miRNA

Figure 2. Pathology of different groups by $\mathrm{H}+\mathrm{E}$ staining $(100 \times)$

${ }^{\star} P<0.05$, compared with NC group; ${ }^{*} p<0.05$, compared with Model group. 
USA); AKT(ab79463, Abcam, USA); p-AKT (ab38449, Abcam, USA); GSK-3ß (ab93926, Abcam, USA), p-GSK-3 $\beta$ (mAb \#5558, Cell Signaling, USA)

\section{Statistical analysis}

The relative data from our study were analyzed by SPSS 20.0 software. The data are shown as mean \pm SD (standard deviation). The significance between multiple sets of data was analyzed by one-way ANOVA with LSD test. $P<0.05$ showed that the difference was statistically significant.

\section{Results}

\section{Clinical data and analysis}

Compared with the NC group, the serum miRNA- 21 gene expression of NEC children was significantly down-regulated $(p<0.05)$. The relative data are shown in Figure 1.

\section{Pathology of difference groups by $\mathrm{H}+\mathrm{E}$ staining}

The pathological score of Model and miRNA groups was significantly higher than that of the NC group ( $p<0.05$, respectively). This result showed that our NEC model was successful. Meanwhile, compared with the Model group, the pathological score of the miRNA group was significantly increased compared with that of the Model group $(p<0.05)$ with miRNA-21 over-expression. The relative data are shown in Figure 2.

\section{Cell apoptosis rate of different groups by TUNEL assay}

Compared with the NC group, the positive apoptosis cell number of the Model group was significantly increased $(p<0.05)$. However, the cell apoptosis rate of the miRNA group was significantly suppressed compared with that of the Model group $(p<0.05)$. The relative data are shown in Figure 3.

\section{Relative protein expression by WB assay}

There were no significantly differences among NC, Model and miRNA groups in PI3K, AKT and GSK-3 $\beta$ protein expression levels. However, compared with the NC group, the PTEN and p-GSK-3 $\beta$ protein expression levels of the Model group were significantly up-regulation ( $p<0.05$, respectively),
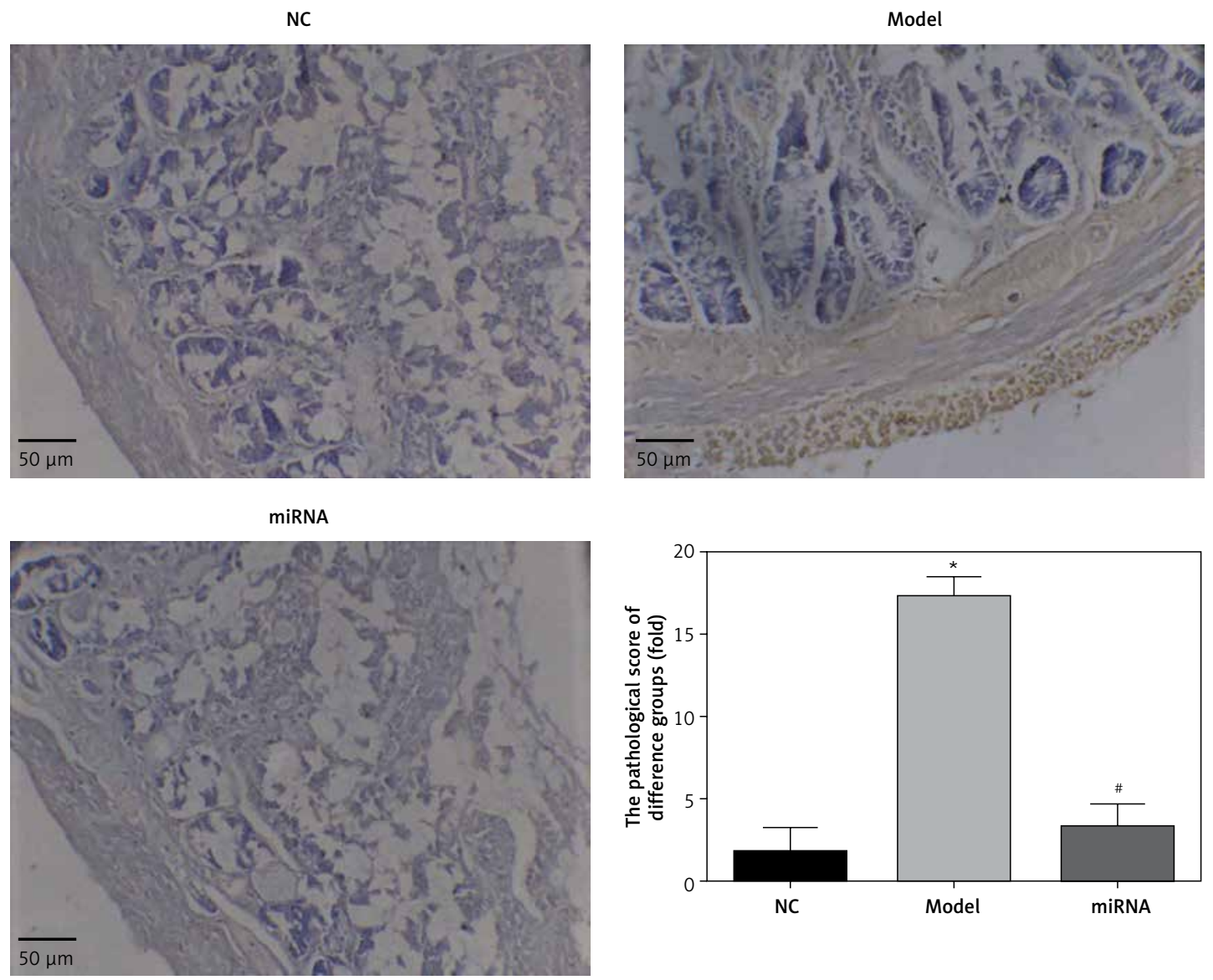

Figure 3. Positive apoptosis cells of different groups by TUNEL assay (200x)

${ }^{*} P<0.05$, compared with NC group; ${ }^{*} p<0.05$, compared with Model group. 
and $\mathrm{p}$-PI3K and $\mathrm{p}-\mathrm{AKT}$ protein expression levels of the Model group were significantly down-regulated ( $p<0.05$, respectively). With miRNA-21 over-expression, the PTEN and $p-G S K-3 \beta$ protein expression levels of the miRNA group were significantly suppressed ( $p<0.05$, respectively), and $\mathrm{p}-\mathrm{PI3K}$ and $\mathrm{p}$-AKT protein expression levels of the miRNA group were significantly increased $(p<0.05$, respectively) compared with the Model group. The relative data are shown in Figure 4.
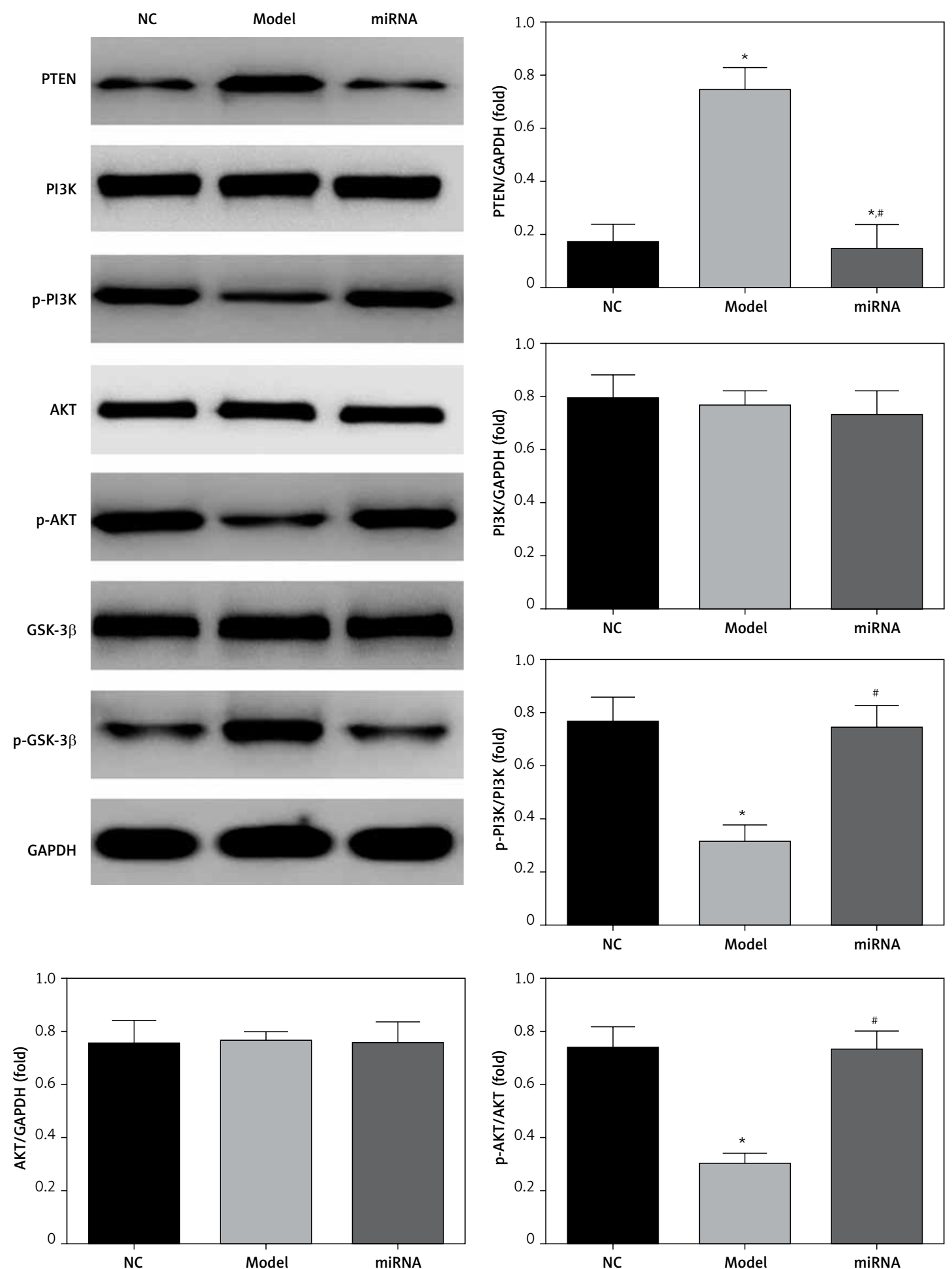

Figure 4. Relative protein expression of different groups by WB assay

${ }^{*} P<0.05$, compared with NC group; ${ }^{*} p<0.05$, compared with Model group. 

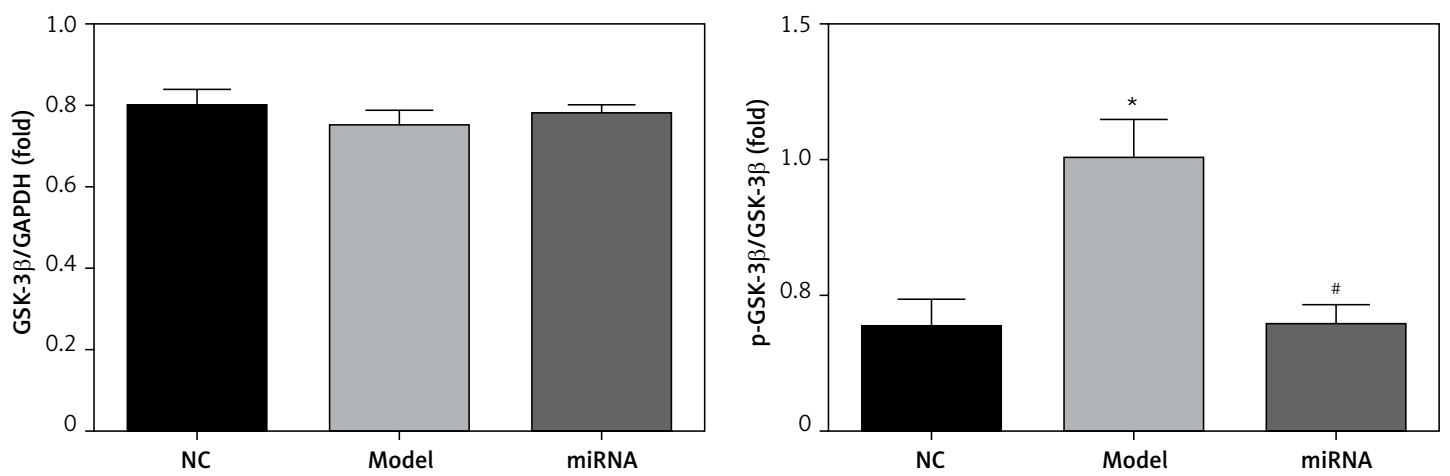

Figure 4. Cont.

${ }^{*} P<0.05$, compared with NC group; ${ }^{*} p<0.05$, compared with Model group.

\section{Discussion}

The NEC is the main effect of low birth weight and low survival rate of the disease and has become very challenging. Although in recent years, many clinical preventive measures such as the increment of enteral feeding and treatment measures based on the standard scheme have resulted in great progress, there is still a risk tendency of premature infants [15]. This experiment mainly simulated the following risk factors of neonatal NEC: ischemia reperfusion injury, hypoxia, hypothermia, artificial feeding, endotoxin caused by hypoxia reoxygenation. Hypoxia, on the one hand, causes diving reflex, redistributes blood and reduces gastrointestinal blood flow and oxygen delivery through adrenaline-induced vasoconstriction; on the other hand, it causes ischemia-reperfusion in jury, which leads to increased intestinal mucosal permeability and eventually intestinal mucosal injury. Hypoxia, endotoxin, and ischemia-reperfusion injury stimulate intestinal Paneth cells to secrete type II phospholipase-A2 (PLA2-II), thus producing platelet-activating factor (PAF) and activating platelet-activating factor receptor (PAFR). Activation of PAFR can activate multiple cytokines including signal transduction and transcription activator of transcription 3 (STAT3) and nuclear factor NF- $\kappa$ B, causing pathological changes, such as vasoconstriction and/or vasodilation, activation and translocation of cytokines, activation of cell adhesion molecules, increase in capillary permeability, production of reactive oxygen species and nitric oxide, as well as increase in intestinal mucosal permeability. PAF by inducing STAT3 phosphorylation and NF- $\mathrm{KB}$ activation induced ileum up-regulation of TLR4. TLR4 increased Notch signaling pathway activated by reduction of goblet cell differentiation. The above pathological changes eventually lead to the occurrence of NEC [16, 17]. Sodhi et al. [18] showed that the TRL4 ${ }^{-1-}$ and conditional destruction of TRL4 in the knockout mice did not occur in
NEC, but the NEC in the wild type mice was more serious. The PTEN/PI3K/AKT signaling pathway and ischemia reperfusion injury, cell proliferation, differentiation, migration, apoptosis, inflammation and so on participate in the process of apoptosis by regulating its downstream signal molecule GSK-3 $\beta$ activity, while the initial NEC pathological process is related to the apoptosis of intestinal tissue cell death [19]. Some scholars have suggested that PTEN/P13K/AKT and its downstream signal molecules may regulate the expression of GSK$3 \beta$ by a negative factor induced by hypoxia in the intestine and can have a protective effect on the intestinal tissue in NEC. GSK-3 $\beta$ widely exists in eukaryotic cells and is involved in transcriptional activation, cell proliferation, cell differentiation and cell movement and other physiological processes. Oxidative stress can activate GSK-3 $\beta$ activation of a pro-apoptotic mechanism [20].

MicroRNAs are a kind of endogenous single stranded molecule found in recent years, nonencoding RNA, size of 18-25 nucleotides, with target mRNA 3'-untranslated region combination at the post-transcriptional level degradation of mRNA or inhibiting mRNA translation, thereby affecting the expression of the target gene [21, 22]. Some previous studies reported that miRNA-21 has an important role in cell apoptosis via regulation of the relative pathway [23-25]. Meanwhile, the studies also found that PTEN was a potential target for miRNA-21 [26, 27]. In our present study, we firstly measured miRNA-21 gene expression in NEC and normal children. The results showed that miRNA-21 gene expression was down-regulated in the NEC children. In the animal experiment, the pathology and cell apoptosis rate were improved in the miRNA-21 over-expression group. This result confirmed that miRNA-21 up-regulation had improved NEC induced pathology and cell apoptosis. In molecular biology, we measured the relative proteins such as PTEN, PI3K, AKT and GSK-3 $\beta$ expression levels. The results showed that PTEN and 
GSK-3 3 , which were two kind roles to improve cell apoptosis [28, 29] were suppressed and the PI3K/ AKT pathway, which was negatively regulatory for cell apoptosis [30], was stimulated.

In conclusion, depending on our results, we inferred that miRNA-21 over-expression can improve NEC induced small intestine tissue necrosis via the PTEN/PI3K/AKT/GSK-3 $\beta$ pathway. miRNA-21 might be a potential target in diagnosis and treatment of NEC.

\section{Acknowledgments}

This study was supported by research funds from Qilu Hospital of Shandong University.

\section{Conflict of interest}

The authors declare no conflict of interest.

\section{References}

1. Dominguez KM, Moss RL. Necrotizing enterocolitis. Clin Perinatol 2012; 39: 387-401.

2. Petrosyan M, Guner YS, Williams M, Grishin A, Ford HR. Current concepts regarding the pathogenesis of necrotizing enterocolitis. Pediatr Surg Int 2009; 25: 309-18.

3. Downard CD, Grant SN, Matheson PJ, et al. Altered intestinal microcirculation is the critical event in the development of necrotizing enterocolitis. J Pediatr Surg 2011; 46: 1023-8.

4. Cetinkaya M, Ozkan H, Koksal N. Maternal preeclampsia is associated with increased risk of necrotizing enterocolitis in preterm infants. Early Hum Dev 2012; 88: 893-8.

5. Saiprasad G, Chitra P, Manikandan R, Sudhandiran G. Hesperidin induces apoptosis and triggers autophagic markers through inhibition of Aurora-A mediated phosphoinositide-3-kinase/Akt/mammalian target of rapamycin and glycogen synthase kinase- 3 beta signalling cascades in experimental colon carcinogenesis. Eur J Cancer 2014; 50: 2489-507.

6. de Araujo WM, Robbs BK, Bastos LG, et al. PTEN overexpression cooperates with lithium to reduce the malignancy and to increase cell death by apoptosis via PI3K/ Akt suppression in colorectal cancer cells. J Cell Biochem 2016; 117: 458-69.

7. McCubrey JA, Rakus D, Gizak A, et al. Effects of mutations in Wnt/beta-catenin, hedgehog, Notch and PI3K pathways on GSK-3 activity-diverse effects on cell growth, metabolism and cancer. Biochim Biophys Acta 2016; 1863: 2942-76.

8. Yang HA, Wang X, Ding F, Pang Q. MiRNA-323-5p promotes U373 cell apoptosis by reducing IGF-1R. Med Sc Monit 2015; 21: 3880-6.

9. Park H, Huang X, Lu C, Cairo MS, Zhou X. MicroRNA-146a and microRNA-146b regulate human dendritic cell apoptosis and cytokine production by targeting TRAF6 and IRAK1 proteins. J Biol Chem 2015; 290: 2831-41.

10. Pan $\mathrm{Y}$, Liang $\mathrm{H}$, Liu $\mathrm{H}$, et al. Platelet-secreted microRNA-223 promotes endothelial cell apoptosis induced by advanced glycation end products via targeting the insulin-like growth factor 1 receptor. I Immunol 2014; 192: 437-46.

11. Zhang C, Shi YR, Liu XR, et al. The anti-apoptotic role of berberine in preimplantation embryo in vitro develop- ment through regulation of miRNA-21. PLoS One 2015; 10: e0129527.

12. Shah S, Jadhav K, Shah V, Gupta N, Dagrus K. miRNA 21 : diagnostic prognostic and therapeutic marker for oral cancer. Microrna 2016; 5: 175-9.

13. Yang Y, Yang JJ, Tao H, Jin WS. MicroRNA-21 controls hTERT via PTEN in human colorectal cancer cell proliferation. J Physiol Biochem 2015; 71: 59-68.

14. Shen W, Chen G, Dong R, Zhao R, Zheng S. MicroRNA-21/ PTEN/Akt axis in the fibrogenesis of biliary atresia. J Pediatr Surg 2014; 49: 1738-41.

15. Baregamian N, Song J, Papaconstantinou J, Hawkins HK, Evers BM, Chung DH. Intestinal mitochondrial apoptotic signaling is activated during oxidative stress. Pediatr Surg Int 2011; 27: 871-7.

16. Soliman A, Michelsen KS, Karahashi H, et al. Plateletactivating factor induces TLR4 expression in intestinal epithelial cells: implication for the pathogenesis of necrotizing enterocolitis. PLoS One 2010; 5: e15044.

17. Aydemir C, Dilli D, Uras N, et al. Total oxidant status and oxidative stress are increased in infants with necrotizing enterocolitis. J Pediatr Surg 2011; 46: 2096-100.

18. Sodhi CP, Neal MD, Siggers R, et al. Intestinal epithelial Toll-like receptor 4 regulates goblet cell development and is required for necrotizing enterocolitis in mice. Gastroenterology 2012; 143: 708-18.

19. Taupin D, Podolsky DK. Trefoil factors: initiators of mucosal healing. Nat Rev Mol Cell Biol 2003; 4: 721-32.

20. Liu GL, Yang HJ, Liu B, Liu T. Effects of microRNA-19b on the proliferation, apoptosis, and migration of Wilms' tumor cells via the PTEN/PI3K/AKT signaling pathway. J Cell Biochem 2017; 118: 3424-34.

21. Ambros $V$. The functions of animal microRNAs. Nature 2004; 431: 350-5.

22. 22.BartelDP.MicroRNAs:targetrecognitionandregulatory functions. Cell 2009; 136: 215-33.

23. Wang XC, Wang W, Zhang ZB, Zhao J, Tan XG, Luo JC. Overexpression of miRNA-21 promotes radiation-resistance of non-small cell lung cancer. Radiat Oncol 2013; 8: 146.

24. Zhang J, Yang Y, Liu Y, et al. MicroRNA-21 regulates biological behaviors in papillary thyroid carcinoma by targeting programmed cell death 4. J Surg Res 2014; 189:

25. Sun Q, Hang M, Guo X, Shao W, Zeng G. Expression and significance of miRNA-21 and BTG2 in lung cancer. Tumour Biol 2013; 34: 4017-26.

26. Liu X, Luo F, Ling M, et al. MicroRNA-21 activation of ERK signaling via PTEN is involved in arsenite-induced autophagy in human hepatic L-02 cells. Toxicol Lett 2016; 252: 1-10.

27. Jiang Q, Han Y, Gao H, Tian R, Li P, Wang C. Ursolic acid induced anti-proliferation effects in rat primary vascular smooth muscle cells is associated with inhibition of miCroRNA- 21 and subsequent PTEN/PI3K. Eur J Pharmacol 2016; 781: 69-75.

28. Yao K, Xing HC, Wu B, et al. Effect of TIEG1 on apoptosis and expression of $\mathrm{Bcl}-2 / \mathrm{Bax}$ and PTEN in leukemic cell lines. Genet Mol Res 2015; 14: 1968-74.

29. Zhang $H$, Wang W, Fang $H$, et al. GSK-3beta inhibition attenuates CLP-induced liver injury by reducing inflammation and hepatic cell apoptosis. Mediators Inflamm 2014; 2014: 629507.

30. Zhang M, Liu Y, Gao Y, Li S. Silibinin-induced glioma cell apoptosis by PI3K-mediated but Akt-independent downregulation of FoxM1 expression. Eur J Pharmacol 2015; 765: 346-54. 